\title{
An overview of the benefits and drawbacks of inhaled corticosteroids in chronic obstructive pulmonary disease
}

This article was published in the following Dove Press journal: International Journal of Chronic Obstructive Pulmonary Disease 16 June 2010

Number of times this article has been viewed

\author{
Sonal Singh' \\ Yoon K Loke ${ }^{2}$ \\ 'Department of Medicine, Johns \\ Hopkins University School of \\ Medicine, Baltimore, Maryland, USA; \\ ${ }^{2}$ School of Medicine, Health Policy \\ and Practice, University of East Anglia, \\ Norwich, England
}

Background: The benefit harm profile of inhaled corticosteroids, and their effect on patient oriented outcomes and comorbid pneumonia, osteoporosis and cardiovascular disease in patients with chronic obstructive pulmonary disease remain uncertain.

Methods: An overview of the evidence on the risks and benefits of inhaled corticosteroids (fluticasone and budesonide) in chronic obstructive pulmonary disease from recent randomized controlled trials and systematic reviews. Observational studies on adverse effects were also evaluated.

Results: Evidence from recent meta-analysis suggests a modest benefit from inhaled corticosteroid long-acting beta-agonist combination inhalers on the frequency of exacerbations, (rate ratio [RR], $0.82 ; 95 \%$ confidence interval [CI]: 0.78 to 0.88 ), in improvements in quality of life measures, and forced expiratory volume in one second when compared to long-acting beta-agonists alone. On the outcome of pneumonia, our updated meta-analysis of trials ( $=24$ trials; RR, 1.56; 95\% CI: 1.40-1.74, $P<0.0001)$ and observational studies ( $\mathrm{n}=4$ studies; RR, 1.44; 95\% CI: $1.20-1.75, P=0.0001$ ) shows a significant increase in the risk of pneumonia with the inhaled corticosteroids currently available (fluticasone and budesonide). Evidence for any intraclass differences in the risk of pneumonia between currently available formulations is inconclusive due to the absence of head to head trials. Inhaled corticosteroids have no cardiovascular effects.

Conclusions: Among patients with chronic obstructive pulmonary disease, clinicians should carefully balance these long-term risks of inhaled corticosteroid against their symptomatic benefits.

Keywords: inhaled corticosteroids, chronic obstructive pulmonary disease, pneumonia, cardiovascular events

\section{Introduction}

Inhaled corticosteroids (ICS) are widely used for the treatment of chronic obstructive pulmonary disease (COPD). They are mainly indicated in combination with a long-acting beta-agonist (LABA) according to the current guidelines in patients with severe COPD and recurrent exacerbations $(>3)$ to decrease the frequency of exacerbations. ${ }^{1}$ The ICS currently available include inhaled fluticasone, inhaled budesonide, and inhaled mometasone, however, none of these are approved for single agent use (ie, without the LABA) in COPD.

ICS are the preferred agents for treatment of asthma. However, the role of ICS in COPD is uncertain. The debate over their optimal role has further intensified with
Correspondence: Sonal Singh ent Medicine, Johns Medicine, 1830 E Monument St, Suite 8063, Baltimore, MD, 21287, USA

Tel + I 4109559869

Fax + I 4109550825

Email ssingh3I@jhu.edu 
the recent publication of several studies suggesting only modest benefit and potential harm. ${ }^{2-4}$

COPD is characterized by a progressive decline in lung function. Additional features such as bronchial hyperresponsiveness and reversibility together with neutrophilic inflammation play an important role in COPD. ${ }^{5,6}$ ICS have been evaluated in several long-term randomized controlled trials (RCTs; usually in combination with a LABA) in the treatment of COPD. ${ }^{7-11}$

Patients with COPD are at risk from underlying comorbidities such as cardiovascular disease, ${ }^{12}$ pneumonia, ${ }^{13,14}$ and osteoporosis. ${ }^{15}$ The potential impact of ICS on these comorbidities in patients with COPD needs careful evaluation. Our objective is to critically review the evidence on the benefits of long-term ICS use on patient oriented outcomes (exacerbations, health-related quality of life), along with their risks in COPD.

\section{Methods}

On completion of our previous systematic review in 2008, ${ }^{4}$ we set up automated weekly electronic updates from PubMed for trial reports of ICS in COPD to update our assessment of any potential adverse effects. For additional outcomes (such as evidence of beneficial effects), we evaluated Cochrane systematic reviews and meta-analysis of RCTs that had been retrieved in our previous searches. We used an intention to treat analysis (all participants analyzed within their randomized intervention group) to update our previous findings on the adverse effects of ICS therapy, based on data in the peer-reviewed publications, and manufacturer's data (for any outcomes that were not fully reported in the published manuscripts). ${ }^{4,16-18}$ Full details of our search strategy and methods of meta-analysis on the adverse effects have been published elsewhere. ${ }^{4,16-18}$

ICS are only indicated in combination with LABAs in COPD. Hence, we evaluated the evidence on the beneficial effect of this comparison against LABAs alone, in RCTs. For the assessment of adverse effects however, we evaluated two separate comparisons: (i) corticosteroid/LABA combination versus LABAs, and (ii) ICS versus placebo. For previously unrecognized adverse effects such as pneumonia, the comparison against placebo provides a clearer insight into the causative agent, which may not be easily apparent in active comparator trials. The evaluation of the combination of ICS and LABAs against placebo does not inform whether any new adverse effects stemmed from the ICS alone, or from a drug interaction with concomitant LABA. We also evaluated the consistency of the evidence on adverse effects from observational studies.

\section{Results \\ Benefits on FEV , frequency of exacerbations, and quality of life}

In contrast to LABAs, the combination of ICS and LABA have been postulated to decrease the frequency of exacerbations, the number of people experiencing exacerbations, improve post-dose forced expiratory volume in one second $\left(\mathrm{FEV}_{1}\right)$, and statistically significant improvements in health related quality of life.

The evidence suggests that ICS in combination with a LABA appear to modestly reduce the risk of exacerbations, when compared to LABAs, by approximately $20 \%-25 \%$ based on evidence from systematic reviews and meta-analysis of RCTs. ${ }^{19-24}$

A Cochrane review of ten trials among participants with severe COPD reported a modest decrease in exacerbation rates with combined inhalers (rate ratio [RR] 0.82; 95\% confidence interval [CI]: 0.78 to 0.88 ), and improvements in quality of life measures and $\mathrm{FEV}_{1}$ compared to LABAs alone. ${ }^{19}$ Another recent meta-analysis from eighteen RCTs reported a similar relative risk reduction in exacerbations. In comparison to LABAs alone, combined ICS and LABA reduced the number of moderate exacerbations (RR, 0.84; 95\% CI: 0.74 to 0.96 ) and provided statistically significant reductions in the St George Respiratory Questionnaire (SGRQ) total score (weighted mean difference, -1.88 ; 95\% CI: -2.44 to -1.33 ) and $\mathrm{FEV}_{1} \cdot{ }^{21}$ Assuming a baseline event rate of 0.97 exacerbations per year, for exacerbations in adult patients with COPD, similar to the placebo event rate in the trial population of the TORCH study, a meta-analysis reported an annualized Number Needed to Treat (NTT) of 6 for exacerbations for ICS when added to LABAs. ${ }^{23}$

However, a network meta-analysis which combined both direct and indirect evidence from 35 RCTs reported no significant difference between ICS combination on exacerbations (odds ratio [OR], 0.93 ; 95\% CI: 0.84 to 1.04 ), when compared to LABAs. ${ }^{22}$

ICS added to LABA, as compared to LABAs alone, have not been conclusively shown to demonstrate clinically significant improvement in measures of health-related quality of life (a decrement of 4 points on the SGRQ questionnaire), exacerbations requiring hospitalizations or overall mortality. ${ }^{11}$ In the absence of individual patient data, it is not possible to determine if there may be certain subgroups of 
participants where there is a more pronounced beneficial effect ( $>4$ points of the SGRQ).

There was no significant effect of ICS combinations on mortality, ${ }^{19,21}$ and lack of significant improvements in severe exacerbations (RR, 0.91 ; 95\% CI: 0.82 to 1.01 ). ${ }^{21} \mathrm{In}$ another meta-analysis reported that the combination of ICS and LABAs reduced mortality when compared to placebo. ${ }^{20}$ However, trials that have shown benefit are limited by the inappropriate statistical analysis of exacerbation rates, comparing patients withdrawing from ICS and not conducting appropriate factorial analysis for $2 \times 2$ trials. ${ }^{25}$ The interpretation of evidence on the benefit of ICS is complicated by the high dropout rate of nearly $30 \%-40 \%$ in COPD trials, and the lack of intention to treat analysis.

\section{Long-term inhaled corticosteroid use and the risk of pneumonia: a class effect}

In early 2009, we reported an approximate $60 \%$ increase in the risk of pneumonia (RR 1.60; 95\% CI: 1.33-1.92, $P<0.001$ ) with the currently available ICS for COPD (fluticasone and budesonide), without an increase in pneumonia related mortality or overall mortality in a multidrug metaanalysis of the class of ICS in COPD. ${ }^{4}$ The limitation of our analysis was the lack of published data on budesonide, with only two budesonide trials included in the meta-analysis.

The paucity of data on budesonide was addressed by the subsequent publication of an industry supported pooled analysis on the risk of pneumonia in 7 budesonide trials which reported a small, though nonstatistically significant excess risk of pneumonia with inhaled budesonide. ${ }^{26}$ The analysis was censored at 1 year despite the availability of data extending up to three years, and included potentially ineligible trials and comparators. ${ }^{17}$ Our re-analysis of the budesonide dataset, addressing these limitations has been published elsewhere. ${ }^{17}$

Our updated intention to treat the meta-analysis of 24 RCTs of the available ICS ( $\mathrm{n}=16$ fluticasone trials, 7 budesonide trials and one mometasone trial) on pneumonia, reported throughout the duration of the trials shows a significantly increased risk of pneumonia within the class of ICS (RR, 1.56 ; 95\% CI: 1.40-1.74, $P<0.0001$ ) similar to our previous analysis. ${ }^{4,17}$ Assuming a baseline event rate of 30 per 1000 person-years for serious pneumonia in adult patients with COPD, similar to the control event rate in the trial population of the TORCH study, the annualized Number Needed to Harm for pneumonia associated with ICS use is estimated to be at 60 (95\% CI, 44-84). The elevated risk remains consistent, irrespective of whether ICS added to LABA (ICS-LABA) was compared to LABA or ICS to placebo. The addition of the recent budesonide data did not change the size and direction of the pooled estimate. Despite the large number of trials, and the inclusion of three different types of ICS, overall heterogeneity was low, raising the possibility of a class effect.

In comparison to fluticasone (16 RCTs), the safety database of inhaled budesonide remains heterogenous, and limited to only seven RCTs and total sample size of nearly $40 \%$ of fluticasone. The relatively low proportion of pneumonia events in the budesonide trials of $\approx 3.5 \%$ in budesonide versus $\approx 6.2 \%$ in fluticasone trials reflects the under ascertainment of pneumonia, and shorter duration of inhaled budesonide exposure, which reduced the power of the budesonide analysis to detect any significant increase in risk of pneumonia. In subgroup analysis, focusing on budesonide exposure, the direction of effect with budesonide was consistent with an increased risk of pneumonia; however, this does not meet the threshold for statistical significance (Figure 1A). Such subgroup analysis for intraclass differences should only be interpreted for their direction of effect.

Substantial heterogeneity was seen in the meta-analysis of budesonide versus placebo, due to presence of two trials with opposing findings - exclusion of either trials eliminated the statistical heterogeneity. ${ }^{7,8}$ One budesonide trial which had a relatively long exposure period (1500 patient years - almost twice as long as the other trials), reported a significant doubling in the risk of pneumonia with inhaled budesonide (RR 2.09; CI: 1.16-3.76) (Figure 1B). ${ }^{7}$ In contrast, the lowest risk estimate for pneumonia (RR 0.67; 95\% CI: 0.37-1.20) stemmed from a trial by Vestbo and colleagues that recruited patients with the mildest severity of COPD and the highest $\mathrm{FEV}_{1}$ of $\approx 80 \% .{ }^{8}$ The authors of the earlier meta-analysis state that "All trials fulfilled our inclusion criteria, except for Vestbo and colleagues'study, which did not include the criterion, that patients had to have at least 10 pack-years smoking history" ${ }^{26}$ Sensitivity analysis excluding this study shows a statistically significantly increased risk of pneumonia with inhaled budesonide (RR, 1.36; 95\% CI: 1.02-1.81, $P=0.04$ ). (Figure 1B)

The presence of substantial heterogeneity signifies that we cannot rule out the possibility that pneumonia is a class effect of ICS use. It is difficult to draw any reliable conclusions on any intraclass differences between fluticasone and budesonide given the paucity of head to head comparisons. Any possible differences in the magnitude of the risk of 


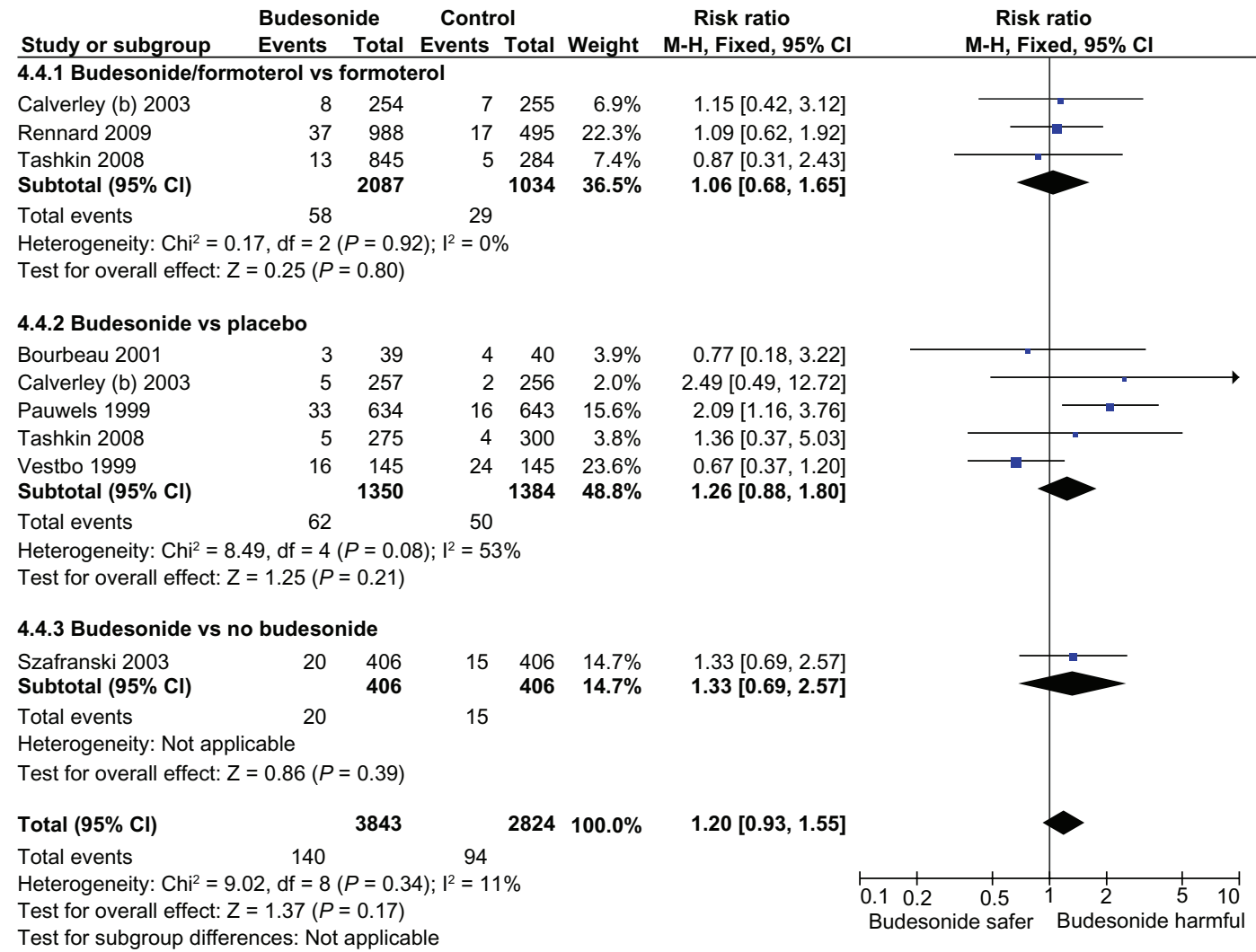

Figure IA Intention to treat meta-analysis of budesonide and the risk of pneumonia in RCTs of COPD (any severity). Abbreviations: COPD, chronic obstructive pulmonary disease; $\mathrm{RCT}$, randomized clinical trial; $\mathrm{Cl}$, confidence interval.

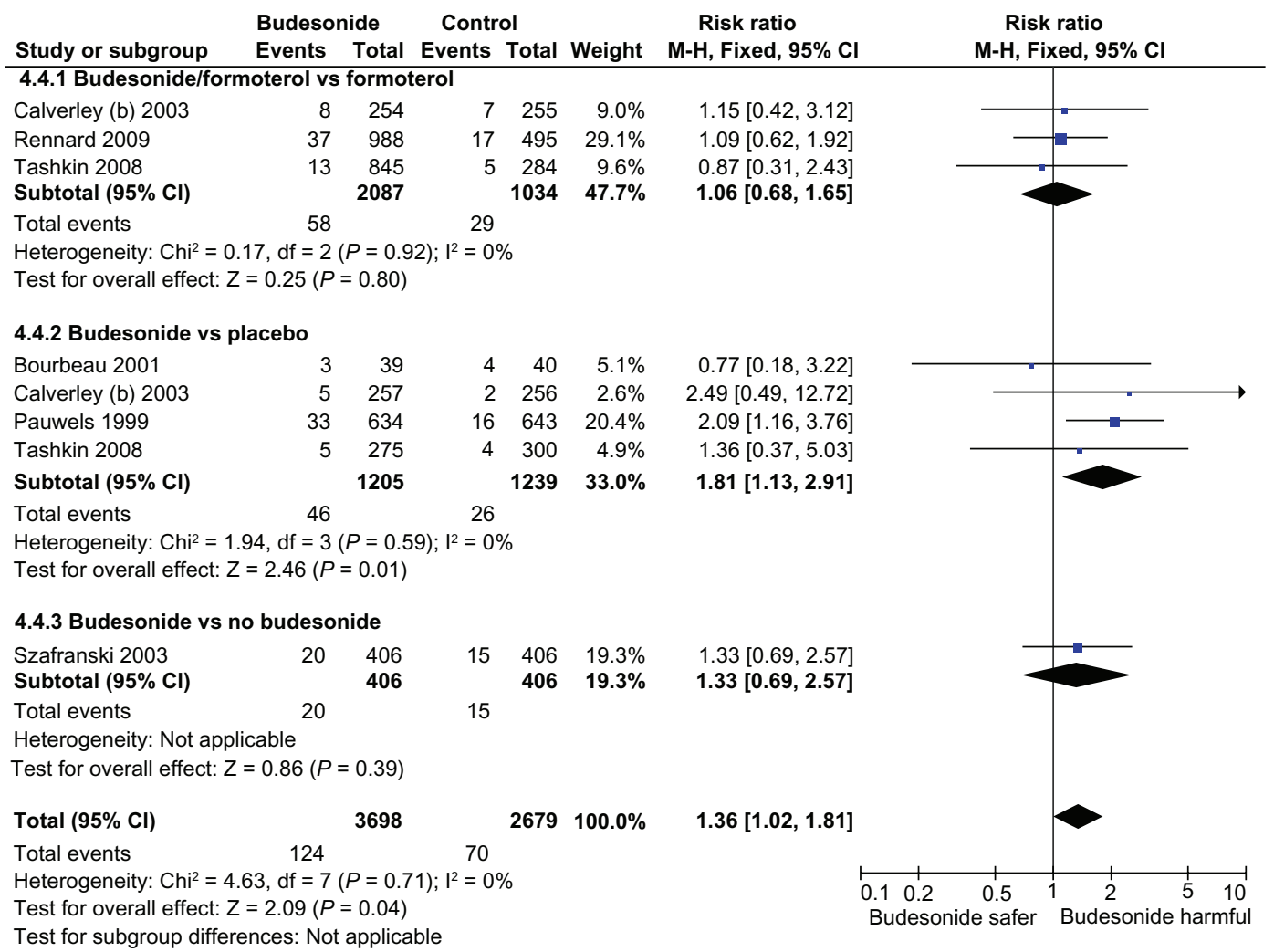

Figure IB Sensitivity analysis of budesonide and the risk of pneumonia with exclusion of study in mild COPD.

Abbreviations: COPD, chronic obstructive pulmonary disease; $\mathrm{RCT}$, randomized clinical trial; $\mathrm{Cl}$, confidence interval. 
pneumonia between fluticasone and budesonide may relate to the weaker potency of inhaled budesonide. ${ }^{26}$

None of these trials were designed to assess the risk of pneumonia and it is unclear if radiographic confirmation was available. However, the increased risk of 'serious' pneumonia (reported as hospitalization, disability or death) increases the robustness of our analysis. ${ }^{17}$ The results of additional reviews are also consistent with the overall evidence confirming a significantly increased risk of pneumonia with ICS. 19,23,24

Four observational studies of ICS on the risk of pneumonia in COPD are available. ${ }^{27-30} \mathrm{An}$ approximate $70 \%$ relative risk increase, in the risk of hospitalization for pneumonia was reported in a population based case-control study from Canada among ICS users in elderly COPD patients compared to nonusers. ${ }^{27}$ Another study in the Veterans Affairs database confirmed an increased risk of pneumonia with ICS. ${ }^{28}$ Two unpublished observational studies reported on the risk of pneumonia with ICS exposure in the General Practice Research Database. ${ }^{29,30}$ These studies reported exposure to all ICSs (including budesonide), although the proportions of patients on each individual agents are unknown. A meta-analysis of the four observational studies shows a significantly increased risk of pneumonia with ICS (RR, 1.44 95\% CI: $1.20-1.75, P<0.0001)$ consistent with the evidence from other trials (Figure 2). The limitations of these studies include the possibility of residual confounding, lack of lung function data, and reliance on dispensing records.

The precise biological mechanism underlying such an increased risk of pneumonia with ICS, and any withinclass differences in risk, are uncertain. Patients aged above 55 years, with severe $\mathrm{COPD}$ and $\mathrm{FEV}_{1}<50 \%$, with a recent history of exacerbations, and those with worse dyspnea scores and lower body mass indexes appear to be at the highest risk of ICS associated pneumonia. ${ }^{31}$ The trials suggest that the increased risk of pneumonia with ICSs are not associated with an increase in pneumonia-related mortality or overall mortality, whereas observational studies which included different study populations reported an increase in pneumonia-related mortality. ${ }^{27}$

\section{Long-term inhaled corticosteroid use and effect of cardiovascular outcomes}

ICS modulates inflammation and were thought to potentially reduce cardiovascular outcomes and mortality in observational studies. ${ }^{16}$ The evidence of cardiovascular benefit in observational studies was contradicted by our robust metaanalysis of 23 RCTs which demonstrated no effect of ICS on myocardial infarction (RR, $0.95 ; 95 \%$ CI: $0.73-1.23$, $P=0.68)$, cardiovascular death (RR, $1.02 ; 95 \% \mathrm{CI}, 0.81-1.27$, $P=0.89, \mathrm{I}^{2}=0 \%$ ), or mortality (RR, 0.96 ; $95 \%$ CI: $0.86-1.07$, $P=0.43)$ in COPD. There was the presence of significant publication bias in the positive findings from previous observational studies, along with residual confounding inherent in epidemiological studies. ${ }^{16}$ Thus, ICSs appear to have no effect on cardiovascular outcomes in COPD.

\section{Effect of ICS on osteoporosis}

A systematic review and meta-analysis which included observational studies among older adults with COPD and asthma found no evidence of an increased fracture risk except among those who used high doses of ICS. ${ }^{32} \mathrm{~A}$ previous meta-analysis of RCTs that reported no increased risk of fractures was limited to 4 trials. ${ }^{32}$ Several observational studies have reported an increased fracture risk with ICS although the evidence is conflicting. ${ }^{32-36}$ However; observational studies are susceptible to confounding by disease severity or higher doses of ICS. ${ }^{37}$ Observational evidence indicates a decline in bone mineral density with ICS use in premenopausal women with asthma ${ }^{37}$ However, analysis from Towards a Revolution in COPD Health (TORCH) reported no significant effect of inhaled fluticasone on bone. ${ }^{38}$ Adequately powered RCTs that determine the risk of fractures with ICS have not been conducted, especially among postmenopausal women with osteoporosis.

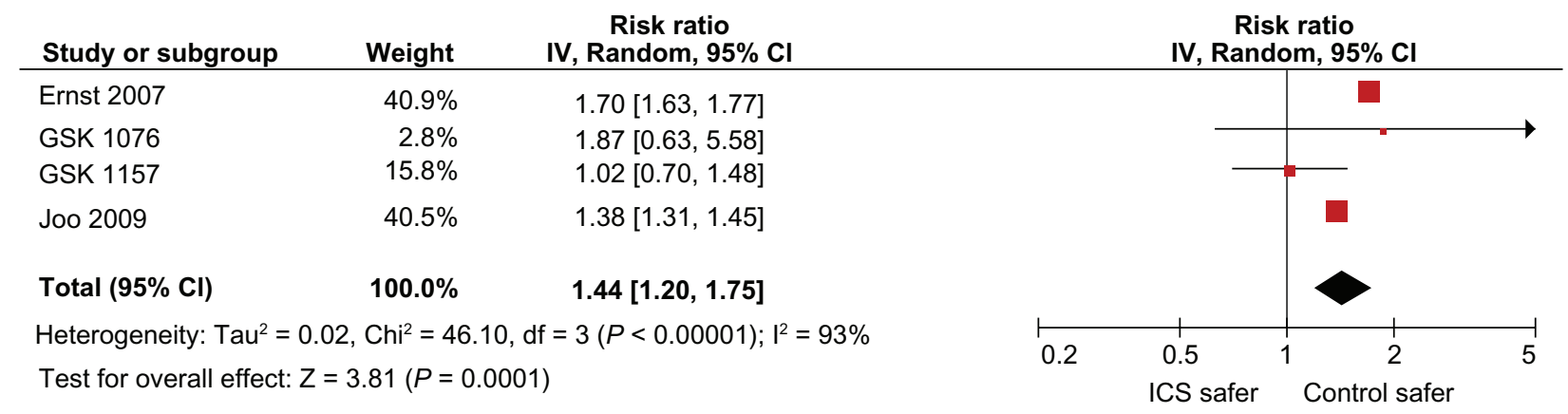

Figure 2 Meta-analysis of inhaled corticosteroids and the risk of pneumonia in observational studies of COPD. Abbreviations: COPD, chronic obstructive pulmonary disease; $\mathrm{Cl}$, confidence interval. 


\section{Cataracts}

Observational studies consistently indicate a modest risk of cataracts, attributable largely to high dosage and long duration of ICS use, consistent with the systemic absorption of ICS..$^{39}$ Although not specific to COPD, a meta-analysis of ICS use in adult patients reported a number needed to harm of 16 [95\% CI, 13-19] with ICS use based on a meta-analysis of epidemiological studies. ${ }^{40}$

\section{Research priorities}

Appropriate factorial analysis of RCTs accounting for the withdrawal of ICS use is needed to determine the true benefit of ICS use. Further research is needed to identify the best way to measure health related quality of life in patients with COPD, as there may be a subset of patients who benefit from ICS in COPD. Robust evidence needs to be generated from adequately powered long term trials to determine if COPD patients with an asthmatic component may derive the greatest benefit from ICS.

Head-to-head long-term trials comparing inhaled fluticasone to budesonide with objective radiographic pneumonia definitions are needed to ascertain any intraclass differences in the risk of pneumonia. These studies should be adequately powered to determine whether pneumonia associated with ICS is truly benign and also identify the specific etiologic agents via microbiologic confirmation. Prospective studies should determine whether the use of antibiotics or specific delivery systems may ameliorate this risk. Adequately powered head to head trials which compare fluticasone to budesonide, each in combination with a LABA, and ascertain cardiovascular outcomes are also needed in COPD.

The absence of conclusive evidence on the harm of fractures from inadequately powered trials should not be construed as proof of safety. Manufacturers of ICSs need to make data from RCTs, available to independent investigators to conduct appropriate intention to treat analysis on any adverse effects without censoring participants.

\section{Overall risk benefit assessment}

The risk benefit profile of ICS should not be considered in isolation, it should consider the risks and benefits of available alternatives. Therapeutic options for patients with COPD are limited although they include LABAs and the class of inhaled anticholinergics. Both LABAs and anticholinergics decrease exacerbations; however, they have been linked to cardiovascular safety concerns. ${ }^{41-45}$ No single therapeutic agent has been conclusively shown to reduce mortality in patients with COPD in any clinical trial. ${ }^{11,46}$ Clinicians should balance the modest benefit on exacerbations when ICSs are added to a LABA against their long term risks of pneumonia.

\section{Disclosures}

The authors report no conflicts of interest relevant to this research. The design and conduct of the study; collection, management, analysis, and interpretation of the data; and preparation, review, or approval of the manuscript was independent of any sources of funding. There were no sources of funding for this work. No specific financial interests and relationships and affiliations relevant to the subject of their manuscript were reported by either author.

Sonal Singh is supported by the Johns Hopkins Clinical Research Scholars Program. This publication was made possible by grant number 1KL2RR025006-03 from the National Center for Research Resources (NCRR), a component of the National Institutes of Health (NIH), and NIH Roadmap for Medical Research. The contents of this review are solely the responsibility of the authors and do not necessarily represent the official view of NCRR or NIH. Information on NCRR is available at http://www.ncrr.nih.gov/. Information on Re-engineering the Clinical Research Enterprise can be obtained from http://nihroadmap.nih.gov/clinicalresearch/ overview-translational.asp.

\section{References}

1. Global Strategy for the Diagnosis, Management and Prevention of COPD, Global Initiative for Chronic Obstructive Lung Disease (GOLD). 2009. http://www.goldcopd.org. Accessed Feb 24, 2010.

2. Suissa S, Barnes PJ. Inhaled corticosteroids in COPD: the case against. Eur Respir J. 2009;34(1):13-16.

3. Postma DS, Calverley P. Inhaled corticosteroids in COPD: a case in favour. Eur Respir J. 2009;34(1):10-12.

4. Singh S, Amin AV, Loke YK. Long-term use of inhaled corticosteroids and the risk of pneumonia in COPD: a meta-analysis. Arch Intern Med. 2009;169(3):219-229.

5. Tashkin DP, Celli B, Decramer M, et al. Bronchodilator responsiveness in patients with COPD. Eur Respir J. 2008;1:742-750.

6. Barnes PJ. Mechanisms in COPD: differences from asthma. Chest. 2000;117 Suppl 2:10S-14S.

7. Pauwels RA, Lofdahl CG, Laitinen LA, et al. Long-term treatment with inhaled budesonide in persons with mild COPD who continue smoking. European Respiratory Society Study on COPD. $N$ Engl J Med. 1999;340:1948-1953.

8. Vestbo J, Sorensen T, Lange P, et al. Long-term effect of inhaled budesonide in mild and moderate COPD: a randomized controlled trial. Lancet. 1999;353:1819-1823.

9. Burge PS, Calverley PM, Jones PW, et al. Randomised, double blind, placebo controlled study of fluticasone propionate in patients with moderate to severe COPD: the ISOLDE trial. BMJ. 2000;320:1297-1303.

10. Lung Health Study Research Group. Effect of inhaled triamcinolone on the decline in pulmonary function in COPD. $N$ Engl J Med. 2000;343:1902-1909.

11. Calverley PMA, Anderson JA, Celli B, et al. Salmeterol and fluticasone propionate and survival in COPD. $N$ Engl J Med. 2007;356(8): $775-789$. 
12. Curkendall SM, DeLuise C, Jones JK, et al. Cardiovascular disease in patients with COPD, Saskatchewan Canada. Ann Epidemiol. 2006;16(1):63-70.

13. Farr BM, Bartlett CL, Wadsworth J, Miller DL. British Thoracic Society Pneumonia Study Group. Risk factors for communityacquired pneumonia diagnosed upon hospital admission. Respir Med. 2000;94:954-963.

14. Restrepo MI, Mortensen EM, Pugh JA, Anzueto A. COPD is associated with increased mortality in patients with community-acquired pneumonia. Eur Respir J. 2006;28(2):346-351.

15. Dam TT, Harrison S, Fink HA, Ramsdell J, Barrett-Connor E. Osteoporotic Fractures in Men (MrOS) Research Group. Bone mineral density and fractures in older men with COPD or asthma. Osteporosis Int. 2009 Oct 9. [Epub ahead of print].

16. Loke YK, Kwok CS, Singh S. Risk of myocardial infarction and cardiovascular death associated with inhaled corticosteroids in COPD: a systematic review and meta-analysis. Eur Respir J. 2010;35(5):1003-1021.

17. Singh S, Loke YK. Risk of pneumonia associated with long-term use of inhaled corticosteroids in COPD: a critical review and update. Curr Opin Pulm Med. 2010;16(2):118-122.

18. Loke YK, Singh S. Inhaled corticosteroids in patients with COPD JAMA. 2009;301(14):1432-1434.

19. Nannini LJ, Cates CJ, Lasserson TJ, Poole P. Combined corticosteroid and long-acting beta-agonist in one inhaler versus long-acting beta-agonists for COPD. Cochrane Database of Systematic Reviews. 2007;4:CD006829.

20. Nannini L, Cates CJ, Lasserson TJ, Poole P. Combined corticosteroid and long-acting beta-agonist in one inhaler versus placebo for COPD. Cochrane Database Syst Rev. 2007;(4):CD003794.

21. Rodrigo GJ, Castro-Rodriguez JA, Plaza V. Safety and efficacy of combined long-acting beta-agonists and inhaled corticosteroids vs long-acting beta-agonists monotherapy for stable COPD: A systematic review. Chest. 2009;136(4):1029-1038.

22. Puhan MA, Bachmann LM, Kleijnen J, Ter Riet G, Kessels AG. Inhaled drugs to reduce exacerbations in patients with COPD: a network metaanalysis. BMC Med. 2009;14:7:2.

23. Sobieraj DM, White CM, Coleman CI. Benefits and risks of adjunctive inhaled corticosteroids in COPD: a meta-analysis. Clin Ther. 2008;30(8):1416-1425.

24. Drummond MB, Dasenbrook EC, Pitz MW, Murphy DJ, Fan E. Inhaled corticosteroids in patients with stable COPD: a systematic review and meta-analysis. JAMA. 2008;300(20):2407-2416.

25. Suissa S, Ernst P, Vandemheen KL, Aaron SD. Methodological issues in therapeutic trials of COPD. Eur Respir J. 2008;31(5):927-933.

26. Sin D, Tashkin D, Xuekui Zhang X, et al. Budesonide and the risk of pneumonia: a meta-analysis of individual patient data. Lancet. 2009;374(9691):712-719.

27. Ernst P, Gonzalez AV, Brassard P, Suissa S. Inhaled corticosteroid use in COPD and the risk of hospitalization for pneumonia. Am J Respir Crit Care Med. 2007;176(2):162-166.

28. Joo MJ, Au DH, Fitzgibbon ML, Lee TA. Inhaled corticosteroids and risk of pneumonia in newly diagnosed COPD. Respir Med. 2010;104(2):246-252.

29. GlaxoSmithKline. Assessment of incidence of pneumonia among COPD patients with or without exposure to inhaled corticosteroids in General Practice Research Database. Available from: http:/www.gskclinicalstudyregister.com/files/pdf/24060.pdf. Accessed Feb 24, 2010.

International Journal of COPD

\section{Publish your work in this journal}

The International Journal of COPD is an international, peer-reviewed journal of therapeutics and pharmacology focusing on concise rapid reporting of clinical studies and reviews in COPD. Special focus is given to the pathophysiological processes underlying the disease, intervention programs, patient focused education, and self management protocols.
30. GlaxoSmithKline. Assessment of incidence of pneumonia among COPD patients on seretide or inhaled corticosteroids in UK primary care. Available from: http://www.gsk-clinicalstudyregister.com/files/ pdf/24056.pdf. Accessed Feb 24, 2010.

31. Crim C, Calverley PM, Anderson JA, et al. Pneumonia risk in COPD patients receiving inhaled corticosteroids alone or in combination: TORCH study results. Eur Respir J. 2009;34(3):641-647.

32. Etminan M, Sadatsafavi M, Ganjizade Zavareh S, Takkouche B, Fitzgerald JM. Inhaled corticosteroids and the risk of fractures in older adults: a systematic review and meta-analysis. Drug Saf. 2008;31(5): 409-414.

33. Hubbard RF, Tattersfield AF, Smith CF, et al. Use of inhaled corticosteroids and the risk of fracture. Chest. 2006;130:1687-1688.

34. Hubbard RB, Smith CJ, Smeeth L, Harrison TW, Tattersfield AE. Inhaled corticosteroids and hip fracture: a population-based case-control study. Am J Respir Crit Care Med. 2002;166:1563-1566.

35. Lee TA, Weiss KB. Fracture risk associated with inhaled corticosteroid use in COPD. Am J Respir Crit Care Med. 2004;169:855-859.

36. Vestergaard P, Rejnmark L, Mosekilde L. Fracture risk in patients with chronic lung diseases treated with bronchodilator drugs and inhaled and oral corticosteroids. Chest. 2007;13(5):1599-1560.

37. Israel E, Banerjee TR, Fitzmaurice GM, et al. Effects of inhaled glucocorticoids on bone density in premenopausal women. $N$ Engl J Med. 2001;345:941-947.

38. Ferguson GT, Calverley PM, Anderson JA, et al. Prevalence and progression of osteoporosis in patients with COPD: results from the towards a revolution in COPD health study. Chest. 2009;136(6):1456-1465.

39. Weatherall M, Clay J, James K, Perrin K, Shirtcliffe P, Beasley R. Doseresponse relationship of inhaled corticosteroids and cataracts: a systematic review and meta-analysis. Respirology. 2009;14(7):983-990.

40. Uboweja A, Malhotra S, Pandhi P. Effect of inhaled corticosteroids on risk of development of cataract: a meta-analysis development of cataract: a meta-analysis. Fundam Clin Pharmacol. 2006;20(3):305-309.

41. Salpeter SR, Buckley NS. Systematic review of clinical outcomes in COPD: beta-agonist use compared with anticholinergics and inhaled corticosteroids. Clin Rev Allergy Immunol. 2006;31(2-3):219-230.

42. Singh S, Loke YK, Furberg CD. Inhaled anticholinergics and risk of major adverse cardiovascular events in patients with COPD: a systematic review and meta-analysis. JAMA. 2008;300(12):1439-1450. (Erratum in JAMA. 2009;301(12):1227-1230).

43. Anthonisen NR, Connett JE, Enright PL, Manfreda J. Lung Health Study Research Group. Hospitalizations and mortality in the Lung Health Study. Am J Respir Crit Care Med. 2002;166(3):333-339.

44. Ogale SS, Lee TA, Au DH, Boudreau DM, Sullivan SD. Cardiovascular events associated with ipratropium bromide in COPD. Chest. 2010;137(1):13-19.

45. Lee TA, Pickard AS, Au DH, Bartle B, Weiss KB. Risk for death associated with medications for recently diagnosed COPD. Ann Intern Med. 2008;149(6):380-390.

46. Tashkin DP, Celli B, Senn S, Burkhart D, Kesten S, Menjoge S, Decramer MUPLIFT Study Investigators. A 4-year trial of tiotropium in COPD. N Engl J Med. 2008;359(15):1543-1554.

\section{Dovepress}

This journal is indexed on PubMed Central, MedLine and CAS. The manuscript management system is completely online and includes a very quick and fair peer-review system, which is all easy to use. Visit http://www.dovepress.com/testimonials.php to read real quotes from published authors. 